\title{
Erosão hídrica em Latossolos Vermelhos distróficos ${ }^{1}$
}

\author{
Joaquim Ernesto Bernardes Ayer ${ }^{2}$, \\ Diogo Olivetti ${ }^{2}$, Ronaldo Luiz Mincato ${ }^{2}$, Marx Leandro Naves Silva ${ }^{3}$
}

\begin{abstract}
\end{abstract}
Water erosion of dystrophic Red Latosols (Oxisols)

In their natural state, Latosols (Oxisols) present great stability and resistance to erosion, being the most abundant and used soils for farming and cattle raising activities in southern Minas Gerais State, Brazil. However, along the last one hundred years, they have been submitted to intensive cultivation and managements which favor water erosion. This study aimed to estimate the water erosion rates of dystrophic Red Latosols from the Revised Universal Soil Loss Equation, compared with the soil loss tolerance limits, and assess the impact on water erosion of the managements more common in the region, by alternative conservation management simulation. Soil loss tolerance limits ranged from $8.94 \mathrm{Mg} \mathrm{ha}^{-1}$ year ${ }^{-1}$ to $9.99 \mathrm{Mg} \mathrm{ha}^{-1}$ year-1, with the study area presenting a susceptibility of soil loss of $23.86 \mathrm{Mg}$ year ${ }^{-1}$, with an average rate of $8.40 \mathrm{Mg} \mathrm{ha}^{-1}$ year $^{-1}$, corresponding to $34.80 \%$ of the area with values above the soil loss tolerance limit. The biggest annual losses occur in areas with use and management of eucalyptus grown downhill (30.67 $\mathrm{Mg} \mathrm{ha}^{-1}$ year $^{-1}$ ) and pasture under continuous occupancy $\left(11.10 \mathrm{Mg} \mathrm{ha}^{-1}\right.$ year $\left.^{-1}\right)$. However, when the average loss per type of use is considered, the areas more susceptible to water erosion are those with potato and eucalyptus crops, grown downhill, and those in bare soil. Nevertheless, in the simulated conservation management scenario, the average losses would be drastically reduced $\left(8.40 \mathrm{Mg} \mathrm{ha}^{-1}\right.$ year- $^{-1}$ to $2.84 \mathrm{Mg} \mathrm{ha}^{-1}$ year $^{-1}$ ) and only $4.00 \%$ of the area with soil loss would remain above the tolerance limits.

KEY-WORDS: Water erosion modeling; no-tillage system; vegetal cover; soil management.

\section{INTRODUÇÃO}

O uso de modelos para a avaliação e mitigação de impactos ambientais é imprescindível frente ao futuro crescimento da população e da demanda por commodities da agropecuária (UNFPA 2012), que deverão acarretar ainda maior pressão sobre os solos. Além disso, no Brasil, 79,6 \% da energia elétrica

\section{RESUMO}

Em estado natural, os Latossolos apresentam grande estabilidade e resistência à erosão, sendo os mais abundantes e utilizados para atividades agropecuárias no sul de Minas Gerais. Contudo, nos últimos cem anos, estes foram submetidos a cultivos e manejos que favorecem a erosão hídrica. Este estudo objetivou estimar as taxas de erosão hídrica em Latossolos Vermelhos distróficos, a partir da Equação Universal de Perdas de Solo Revisada, em comparação com os limites de tolerância de perda de solo, e avaliar o impacto sobre a erosão hídrica dos manejos mais utilizados na região, pela simulação de alternativas de manejos conservacionistas. Os limites de tolerância de perda de solo variaram de $8,94 \mathrm{Mg} \mathrm{ha}{ }^{-1}$ ano $^{-1}$ a 9,99 $\mathrm{Mg} \mathrm{ha}^{-1} \mathrm{ano}^{-1}$, sendo que a área estudada apresenta suscetibilidade de perda de solo de 23,86 Mg ano-1 com taxa média de $8,40 \mathrm{Mg} \mathrm{ha}^{-1} \mathrm{ano}^{-1}$, correspondendo a $34,80 \%$ da área com valores acima do limite de tolerância de perda de solos. As maiores perdas anuais ocorrem nas áreas com uso e manejo de eucalipto $\left(30,67 \mathrm{Mg} \mathrm{ha}^{-1} \mathrm{ano}^{-1}\right)$, com plantio morro abaixo, e pastagem sob lotação contínua $\left(11,10 \mathrm{Mg} \mathrm{ha}^{-1} \mathrm{ano}^{-1}\right)$. Todavia, quando é considerada a perda média por tipo de uso, as áreas mais suscetíveis à erosão hídrica são as ocupadas pelas culturas de batata e eucalipto, com plantio morro abaixo, e as de solos expostos. Entretanto, no cenário simulado com manejo conservacionista, as perdas médias seriam reduzidas drasticamente $\left(8,40 \mathrm{Mg} \mathrm{ha}^{-1} \mathrm{ano}^{-1}\right.$ para $\left.2,84 \mathrm{Mg} \mathrm{ha}^{-1} \mathrm{ano}^{-1}\right)$ e restariam somente 4,00 \% da área com perdas de solo acima do limite de tolerância.

PALAVRAS-CHAVE: Modelagem de erosão hídrica; sistema plantio direto; cobertura vegetal; manejo do solo.

é de origem hidráulica (Brasil 2013), o que torna essenciais os estudos sobre a erosão, para mitigar o assoreamento de reservatórios (Carvalho 2008).

A ação antrópica altera o equilíbrio natural entre as taxas de formação e erosão dos solos, podendo intensificar os processos erosivos (Brady \& Weil 2013). Deve-se considerar que os solos não são renováveis na escala de tempo humana e que o

1. Trabalho recebido em jul./2014 e aceito para publicação em mai./2015 (http://dx.doi.org/10.1590/1983-40632015v4531197).

2. Universidade Federal de Alfenas (Unifal-MG), Instituto de Ciências da Natureza, Alfenas, MG, Brasil.

E-mails: joaquimeba@yahoo.com.br,di_olivetti@hotmail.com, ronaldo.mincato@unifal-mg.edu.br.

3. Universidade Federal de Lavras (UFLa), Departamento de Ciência do Solo, Lavras, MG, Brasil.E-mail: marx@dcs.ufla.br. 
manejo inadequado resulta em erosão acelerada, com perdas de solo, nutrientes, água e matéria orgânica, que prejudicam a capacidade produtiva dos solos (Morgan \& Nearing 2011).

Há diversas equações e modelos para avaliação dos fatores que afetam as perdas de solo por erosão hídrica ou outros agentes erosivos. Entretanto, a quantificação da erosão hídrica pela Equação Universal de Perdas de Solos (Universal Soil Loss Equation - USLE), de Wischmeier \& Smith (1978), tem maior aplicabilidade, em relação aos modelos físicos e conceituais. Por superar, em parte, as restrições climáticas e geográficas, principalmente após o desenvolvimento da versão revisada (Revised Universal Soil Loss Equation - RUSLE), de Renard et al. (1997), e pela utilização de sistemas de informação geográfica (SIG), sensoriamento remoto e métodos geoestatísticos modernos para cálculo dos fatores da USLE/RUSLE, tem sido possível a sua aplicação em ambientes mais complexos, como bacias hidrográficas (Morgan \& Nearing 2011). A USLE e a RUSLE são, ainda, os modelos mais utilizados no Brasil (Barretto et al. 2008, Beskow et al. 2009, Avanzi et al. 2013).

Os usos e manejos convencionais do solo ainda dominantes no sul de Minas Gerais utilizam aragem, gradagem e, em algumas situações, escarificação dos solos, além de plantio mecanizado na agricultura e lotação contínua na pecuária, o que resulta em elevadas taxas de perda de solo. Devido ao desmatamento, atualmente, o sul de Minas Gerais apresenta apenas cerca de 4,0\% da cobertura vegetal nativa (INPE 2013). Essas características, aliadas à carência de manejos e práticas conservacionistas eficientes, como o plantio direto, causam a degradação dos atributos dos solos (Bertoni \& Lombardi Neto 2008) e podem elevar as perdas de solo acima do limite de tolerância de perda de solo (TPS) de cada área. A erosão promove o assoreamento dos corpos d'água e a contaminação dos recursos hídricos, já tão escassos no atual contexto de mudanças climáticas. Além disso, o processo erosivo também prejudica a cadeia trófica pelo carreamento de insumos agrícolas (Londres 2011).

A simulação da aplicação de sistemas de manejo alternativos pode apontar soluções para mitigar o problema da erosão, indicando sistemas que conciliem a preservação dos recursos naturais e a produção agrícola sustentável em longo prazo. Nessa perspectiva, Zolin et al. (2011) demonstraram tanto a eficiência da simulação de cenários para análises e proposição de medidas para mitigação da erosão quanto a eficácia da medida de Pagamentos por Serviços Ambientais, na sub-bacia hidrográfica de Posses.

Assim, a estimativa da erosão de Latossolos pela RUSLE, na sub-bacia do Córrego Pedra Branca, Alfenas, contribui com os estudos sobre o tema no sul de Minas Gerais, como, por exemplo, os de Beskow et al. (2009) e Avanzi et al. (2013). Essa região apresenta recursos hídricos estratégicos para dessedentação, irrigação e produção de energia elétrica. Além disso, a região é a principal produtora mundial de café e uma das principais produtoras de milho e de leite do País, sendo responsável pela maior parte do produto interno bruto da agropecuária estadual (FJP 2009). Pela localização geográfica, a região atua como celeiro e fornecedor de energia para importantes regiões metropolitanas brasileiras, como São Paulo, Rio de Janeiro e Belo Horizonte.

Diante da escassez de estudos que relacionem os sistemas de manejo com as perdas de solo, e considerando-se a importância dos Latossolos para a agropecuária do sul de Minas Gerais, este trabalho objetivou avaliar a erosão hídrica e simular cenários com a adoção de sistemas de manejo conservacionistas, na sub-bacia hidrográfica do Córrego Pedra Branca.

\section{MATERIAL E MÉTODOS}

O estudo foi realizado de março de 2011 a fevereiro de 2014, na sub-bacia hidrográfica do Córrego

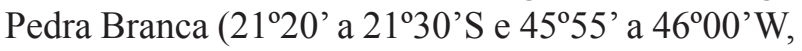
Datum WGS zona $23 \mathrm{Sul}$ ), no Município de Alfenas (MG) (Figura 1), com altitudes de 920-780 m e área total de 2.642 ha.

A sub-bacia faz parte da Bacia do Rio Grande e é afluente do reservatório da Usina Hidrelétrica de Furnas, que abrange vários municípios do sul de Minas Gerais. De acordo com a classificação de Köppen, o clima é Tropical Mesotérmico (CwB) (Sparovek et al. 2007), com precipitação média anual de $1.500 \mathrm{~mm}$.

A sub-bacia encontra-se em uma superfície com elevações de contornos arredondados, vertentes longas, vales abertos e pequenos desnivelamentos locais. É composta por gnaisses charnoquíticos e granulíticos polimetamórficos proterozoicos (Hasui 2010), que formam o Planalto Sul de Minas, na unidade fisiográfica dos mares de morros.

A Figura 1 ilustra, ainda, o mapa de unidades de solos discriminadas a partir da classificação digital 


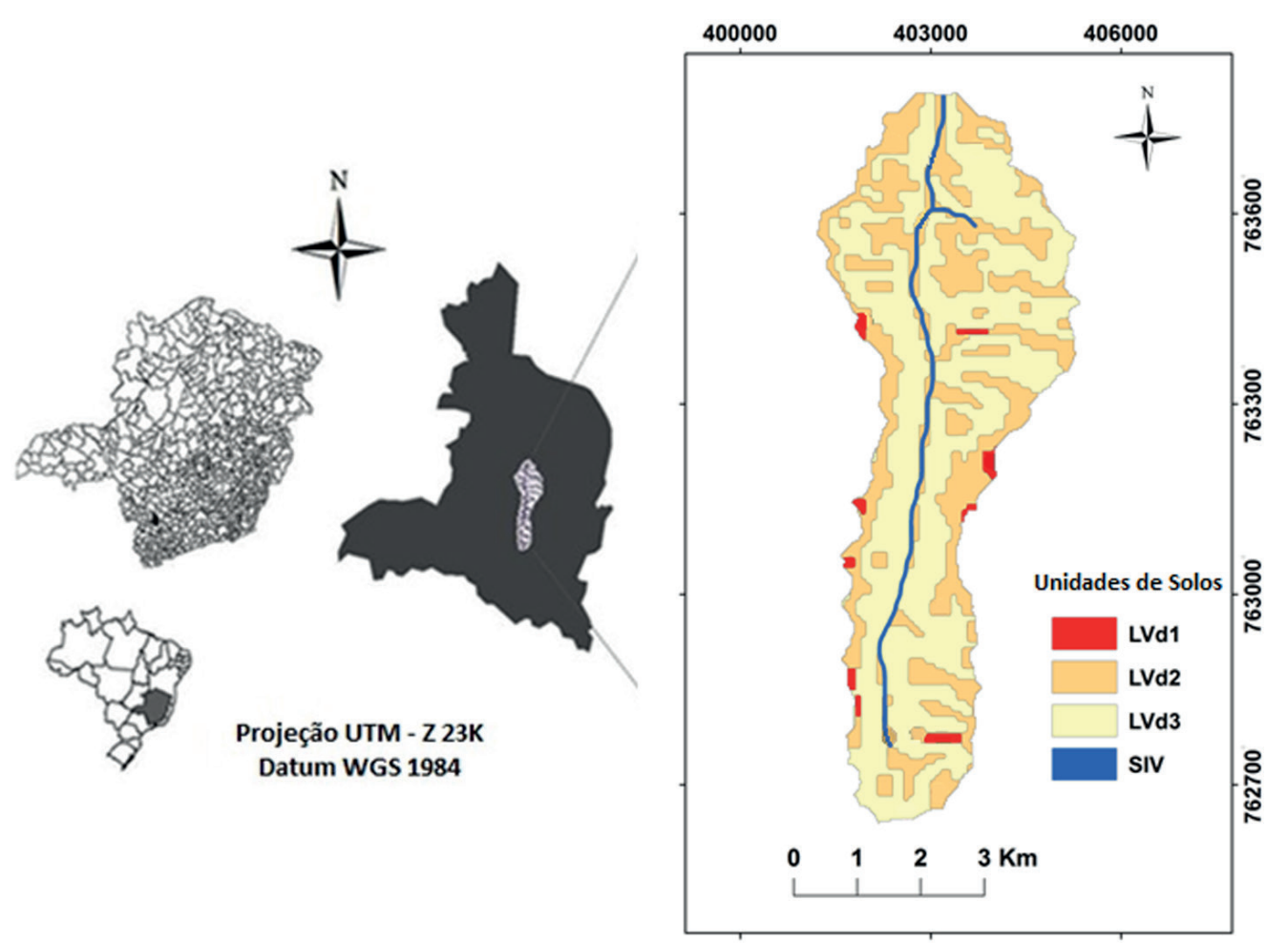

Figura 1. Mapa de localização das unidades de solos da sub-bacia hidrográfica do Córrego Pedra Branca (Alfenas, MG, 2014). LVd1: Latossolo Vermelho distrófico em relevo plano; LVd2: Latossolo Vermelho distrófico em relevo suave ondulado; LVd3: Latossolo Vermelho distrófico em relevo ondulado; SIV: Solos Indiscriminados de Várzea, onde predominam Gleissolos distróficos.

dos solos obtido pelo cruzamento do Mapa de Solos do Estado de Minas Gerais (Minas Gerais 2010) com as unidades de relevo obtidas do mapa de declividade do Modelo Digital de Elevação (MDE). Este modelo foi derivado do Shuttle Radar Topography Mission (SRTM), usando as classes de declive da Embrapa (2006), com auxílio do programa ArcGIS 10.0.

As unidades de mapeamento definidas foram: Latossolo Vermelho distrófico, nos relevos planos (LVd1), suave ondulados (LVd2) e ondulados (LVd3), e Solos Indiscriminados de Várzea (SIV), com predomínio de Gleissolos distróficos, nas planícies aluviais, identificadas em campo (Figura 1). Cada unidade ocupa, respectivamente, $1,5 \%, 33,8 \%$, $56,5 \%$ e $8,3 \%$ da área da sub-bacia.

De outubro de 2012 a abril de 2013, foram coletadas, com e sem estrutura alterada, em cada unidade de solo, quatro amostras, na camada de 0-0,20 m, para obtenção dos atributos físicos, químicos e morfológicos dos solos.

Os atributos obtidos foram: cor, utilizando-se Caderneta de Munsel; textura e argila dispersa em água, pelo método do densímetro (Black 1986), conforme diâmetro das partículas (Embrapa 1998); índice de floculação (Embrapa 1998); permeabilidade do solo à água, com infiltrômetro de campo (Zhang 1997, Dane \& Topp 2002); e estabilidade de agregados, pelo método de tamisamento em água (peneiras com diâmetro de malha de 5,0 mm; $1,5 \mathrm{~mm} ; 0,75 \mathrm{~mm}$; $0,375 \mathrm{~mm} ; 0,1775 \mathrm{~mm}$; e 0,0525 mm) (Kemper \& Rosenau 1986), e destes foi obtido o diâmetro médio ponderado (DMP) e geométrico (DMG) (Tabela 1), conforme Kemper \& Chepil (1965), pelas equações $\mathrm{DMP}=\sum \mathrm{x}_{\mathrm{i}} D M_{\mathrm{i}}$ e DMG $=10^{\sum \mathrm{x}_{\mathrm{i}} \log \left(\mathrm{DM}_{\mathrm{i}}\right)}$, em que $\mathrm{x}_{\mathrm{i}}$ é a proporção de agregados de cada classe, em relação ao total, e $\mathrm{DM}_{\mathrm{i}}$ é o diâmetro médio de cada classe de agregados.

Do complexo sortivo, foram determinados: pH em água, $\mathrm{KCl}$ e $\mathrm{CaCl}_{2}$ - relação 1:2,5; $\mathrm{Ca}-\mathrm{Mg}-\mathrm{Al}$, com extrator $\mathrm{KC} 11 \mathrm{~mol} \mathrm{~L}^{-1}$; fósforo remanescente (P-rem); matéria orgânica (MO), por oxidação com $\mathrm{Na}_{2} \mathrm{Cr}_{2} \mathrm{O}_{7} 2 \mathrm{~mol} \mathrm{~L}^{-1}+\mathrm{H}_{2} \mathrm{SO}_{4} 5 \mathrm{~mol} \mathrm{~L}^{-1}$; e $\mathrm{K}$, com extrator Mehlich 1. A partir desses dados, foram calculados a soma de bases trocáveis (SB); capacidade de troca catiônica (CTC-T) a $\mathrm{pH} 7,0$; capacidade de troca catiônica efetiva (CTC-t); índice de satu- 
Tabela 1. Caracterização física e química das unidades de solos da sub-bacia hidrográfica do Córrego Pedra Branca (Alfenas, MG, 2014).

\begin{tabular}{|c|c|c|c|c|}
\hline \multirow{2}{*}{ Atributos solos } & \multicolumn{4}{|c|}{ Valor médio } \\
\hline & Unidade LVd1 & Unidade LVd2 & Unidade LVd3 & Unidade SIV \\
\hline X1 - Matiz do solo úmido (adimensional) & $2,000 *$ & $2,000 *$ & $2,000 *$ & $2,000 *$ \\
\hline X2 - Tipo de estrutura (adimensional) & $3,000 *$ & $3,000 *$ & $3,000 *$ & $3,000 *$ \\
\hline X3 - Grau da estrutura (adimensional) & $2,000 *$ & $2,000 *$ & $2,000 *$ & $2,000 *$ \\
\hline X4 - Forma da estrutura (adimensional) & $1,000^{*}$ & $1,000^{*}$ & $1,000 *$ & $2,000 *$ \\
\hline X5 - Plasticidade do solo (adimensional) & $2,000 *$ & $2,000 *$ & $2,000 *$ & $3,000 *$ \\
\hline X6 - Teor de AMG dispersa com NaOH $0,1 \mathrm{~mol} \mathrm{~L}^{-1}\left(\mathrm{~g} \mathrm{~kg}^{-1}\right)$ & 40,000 & 40,000 & 50,000 & 100,000 \\
\hline X7 - Teor de AG dispersa com NaOH 0,1 mol L-1 $\left(\mathrm{g} \mathrm{kg}^{-1}\right)$ & 100,000 & 100,000 & 130,000 & 220,000 \\
\hline $\mathrm{X} 8$ - Teor de AM dispersa com $\mathrm{NaOH} 0,1 \mathrm{~mol} \mathrm{~L}^{-1}\left(\mathrm{~g} \mathrm{~kg}^{-1}\right)$ & 110,000 & 140,000 & 130,000 & 140,000 \\
\hline X9 - Teor de AF dispersa com NaOH 0,1 mol L-1 $\left(\mathrm{g} \mathrm{kg}^{-1}\right)$ & 100,000 & 140,000 & 110,000 & 90,000 \\
\hline X10 - Teor de AMF dispersa com NaOH 0,1 mol L-1 $\left(\mathrm{g} \mathrm{kg}^{-1}\right)$ & 30,000 & 40,000 & 40,000 & 40,000 \\
\hline $\mathrm{X} 11$ - Teor de silte disperso com $\mathrm{NaOH} 0,1 \mathrm{~mol} \mathrm{~L}^{-1}\left(\mathrm{~g} \mathrm{~kg}^{-1}\right)$ & 50,000 & 50,000 & 70,000 & 110,000 \\
\hline $\mathrm{X} 12$ - Teor de argila dispersa com $\mathrm{NaOH} 0,1 \mathrm{~mol} \mathrm{~L}^{-1}\left(\mathrm{~g} \mathrm{~kg}^{-1}\right)$ & 570,000 & 490,000 & 470,000 & 300,000 \\
\hline X13 - Teor de AMG dispersa em água $\left(\mathrm{g} \mathrm{kg}^{-1}\right)$ & 30,000 & 30,000 & 40,000 & 70,000 \\
\hline X14 - Teor de AG dispersa em água $\left(\mathrm{g} \mathrm{kg}^{-1}\right)$ & 100,000 & 100,000 & 110,000 & 180,000 \\
\hline X15 - Teor de AM dispersa em água $\left(\mathrm{g} \mathrm{kg}^{-1}\right)$ & 140,000 & 150,000 & 140,000 & 150,000 \\
\hline X16 - Teor de AF dispersa em água $\left(\mathrm{g} \mathrm{kg}^{-1}\right)$ & 150,000 & 180,000 & 140,000 & 90,000 \\
\hline X17 - Teor de AMF dispersa em água $\left(\mathrm{g} \mathrm{kg}^{-1}\right)$ & 40,000 & 60,000 & 50,000 & 40,000 \\
\hline X18 - Teor de silte disperso em água $\left(\mathrm{g} \mathrm{kg}^{-1}\right)$ & 140,000 & 140,000 & 180,000 & 280,000 \\
\hline $\mathrm{X} 19$ - Teor de argila dispersa em água $\left(\mathrm{g} \mathrm{kg}^{-1}\right)$ & 400,000 & 340,000 & 340,000 & 190,000 \\
\hline $\mathrm{X} 20$ - DMP (mm) & 3,642 & 3,710 & 2,847 & 3,395 \\
\hline $\mathrm{X} 21-\mathrm{DMG}(\mathrm{mm})$ & 4,030 & 4,352 & 3,685 & 4,144 \\
\hline $\mathrm{X} 22$ - Permeabilidade do solo à água $\left(\mathrm{mm} \mathrm{h}^{-1}\right)$ & 17,060 & 58,980 & 56,200 & 22,990 \\
\hline X23 - Índice de floculação (adimensional) & 28,000 & 28,000 & 27,000 & 40,000 \\
\hline X24 - Teor de MO $\left(\mathrm{g} \mathrm{kg}^{-1}\right)$ & 31,600 & 25,700 & 23,600 & 28,500 \\
\hline $\mathrm{X} 25-\mathrm{pH}$ (adimensional) & 5,080 & 4,880 & 4,700 & 4,970 \\
\hline $\mathrm{X} 26-\mathrm{K}\left(\mathrm{mg} \mathrm{dm} \mathrm{m}^{-3}\right)$ & 80,500 & 32,500 & 47,000 & 54,670 \\
\hline $\mathrm{X} 27-\mathrm{P}\left(\mathrm{mg} \mathrm{dm}^{-3}\right)$ & 1,810 & 1,130 & 1,870 & 3,840 \\
\hline $\mathrm{X} 28-\mathrm{Ca}\left(\mathrm{cmol}_{\mathrm{c}} \mathrm{dm}^{-3}\right)$ & 0,800 & 0,630 & 0,830 & 1,800 \\
\hline $\mathrm{X} 29-\mathrm{Mg}\left(\mathrm{cmol}_{\mathrm{c}} \mathrm{dm}^{-3}\right)$ & 0,330 & 0,230 & 0,380 & 0,530 \\
\hline $\mathrm{X} 30-\mathrm{Al}\left(\mathrm{cmol}_{\mathrm{c}} \mathrm{dm}^{-3}\right)$ & 0,930 & 0,700 & 0,950 & 0,530 \\
\hline $\mathrm{X} 31-\mathrm{H}+\mathrm{Al}\left(\mathrm{cmol}_{\mathrm{c}} \mathrm{dm}^{-3}\right)$ & 8,500 & 6,750 & 7,940 & 6,490 \\
\hline $\mathrm{X} 32-\mathrm{V}(\%)$ & 16,120 & 12,080 & 15,000 & 28,400 \\
\hline X33 - CTC-t $\left(\mathrm{cmol}_{\mathrm{c}} \mathrm{dm}^{-3}\right)$ & 2,260 & 1,630 & 2,270 & 3,010 \\
\hline X34 - CTC-T a pH $7,0\left(\mathrm{cmol}_{\mathrm{c}} \mathrm{dm}^{-3}\right)$ & 9,840 & 7,690 & 9,260 & 8,960 \\
\hline $\mathrm{X} 35-\mathrm{m}(\%)$ & 44,120 & 43,720 & 42,900 & 23,550 \\
\hline $\mathrm{X} 36-\mathrm{SB}\left(\mathrm{cmol}_{\mathrm{c}} \mathrm{dm}^{-3}\right)$ & 1,330 & 0,940 & 1,320 & 2,470 \\
\hline $\mathrm{X} 37$ - P-rem $\left(\mathrm{mg} \mathrm{L}^{-1}\right)$ & 12,150 & 13,580 & 13,710 & 23,140 \\
\hline
\end{tabular}

$\mathrm{AMG}=$ areia muito grossa; $\mathrm{AG}=$ areia grossa $\mathrm{AM}=$ areia média; $\mathrm{AF}=$ areia fina; $\mathrm{AMF}=$ areia muito fina; $\mathrm{DMG}=$ diâmetro médio geométrico; $\mathrm{DMP}=$ diâmetro médio ponderado; $\mathrm{SB}=$ soma de bases trocáveis; $\mathrm{CTC}-\mathrm{T}=$ capacidade de troca catiônica; $\mathrm{CTC}-\mathrm{t}=$ capacidade de troca catiônica efetiva; $\mathrm{MO}=$ matéria orgânica; $\mathrm{m}=$ índice de saturação por alumínio; P-rem = fósforo remanescente; $\mathrm{V}=$ índice de saturação por bases. * Dados codificados de Silva et al. (1999).

ração de alumínio (m); H + Al, com extrator SMP; e índice de saturação de bases (V) (Embrapa 1998) (Tabela 1).

A perda de solo (A), na sub-bacia do Córrego Pedra Branca, foi calculada pela RUSLE, de acordo com método descrito por Renard et al. (1997), subsidiado pelo SIGArcGIS 10.0: $\mathrm{A}=\mathrm{R} * \mathrm{~K} * \mathrm{~L} * \mathrm{~S} * \mathrm{C} * \mathrm{P}$, em que "A" é a perda de solo $\left(\mathrm{Mg} \mathrm{ha}^{-1} \mathrm{ano}^{-1}\right)$; "R" a erosividade da chuva (MJ mm ha-1 $\mathrm{h}^{-1} \mathrm{ano}^{-1}$ ); "K" a erodibilidade do solo $\left(\mathrm{Mg} \mathrm{ha}^{-1} \mathrm{MJ}^{-1} \mathrm{~mm}^{-1}\right)$; " $\mathrm{L}$ " e "S" o fator topográfico, pela relação entre a declividade e o comprimento de rampa (adimensionais); e "C" e "P", respectivamente, os fatores cobertura e manejo dos solos e vigência de práticas conservacionistas (adimensionais) (Wischmeier \& Smith 1978).

O fator " $K$ " foi obtido pelo método indireto de avaliação de erodibilidade de Latossolos de Silva et al. (1999), a partir dos dados da Tabela 1, para as três unidades de Latossolos, como se segue: $\mathrm{K}=4,77 \mathrm{x}$ $10^{-2}-9,66 \times 10^{-3} \mathrm{X} 1+1,63 \times 10^{-2} \mathrm{X} 2-1,12 \times 10^{-2} \mathrm{X} 3+$ 
$1,85 \times 10^{-2} \mathrm{X} 4-1,51 \times 10^{-2} \mathrm{X} 5-2,46 \times 10^{-4} \mathrm{X} 9-3,58 \times$ $10^{-4} \mathrm{X} 10+1,47 \times 10^{-4} \mathrm{X} 11-1,43 \times 10^{-4} \mathrm{X} 12+3,26 \mathrm{x}$ $10^{-3} \mathrm{X} 13-1,26 \times 10^{-3} \mathrm{X} 14-2,29 \times 10^{-4} \mathrm{X} 18+1,07 \times$ $10^{-4} \times 19+2,69 \times 10^{-4} \times 23$.

O fator "R" foi obtido de Aquino et al. (2012), que, a partir de 54 estações pluviométricas, calcularam a erosividade da chuva e efetuaram a interpolação para o sul de Minas Gerais. A área estudada apresenta valor único de erosividade na ordem de 6.500 $\mathrm{MJ} \mathrm{mm} \mathrm{ha}^{-1} \mathrm{~h}^{-1}$ ano $^{-1}$.

O fator topográfico (LS) foi calculado a partir da equação USPED (Unit Stream Power Erosion and Deposition) (Moore \& Burch 1986), a qual possui variáveis que representam os tipos de fluxos de escoamento superficial (linear e laminar), ou seja, avaliam a erosão total na área (Oliveira et al. 2013). Foi utilizada a extensão TauDEM 5.0 (Tarboton \& Mohammed 2010), adicionada ao SIG ArcGIS 10.0, para delimitação automática da sub-bacia, e cálculo do escoamento superficial pelo método D $\infty$ de Tarboton (1997). Este método é considerado de maior acurácia para identificação de escoamento de fluxos (Oliveira et al. 2013). Deste, foi obtida a área de contribuição, que permite mapear tanto áreas onde predomina o escoamento quanto a acumulação dos fluxos.

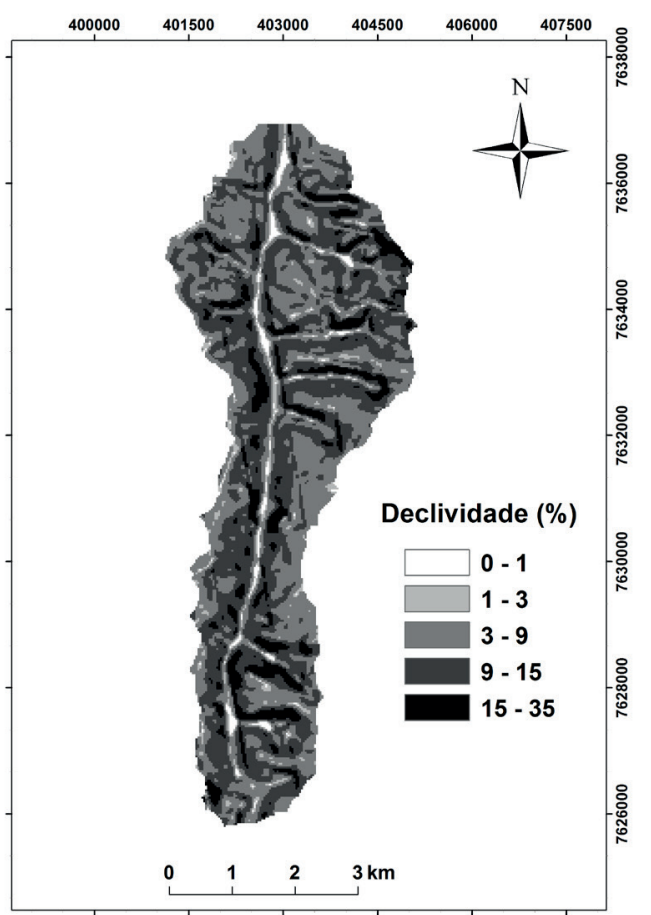

A área de contribuição e a declividade da sub-bacia foram relacionadas pela função Raster Calculator do SIG ArcGIS 10.0. Tais dados derivaram do MDE Topodata, filtrado pela função PIT do TauDEM 5.0, que remove os pixels com valores anômalos. O MDE Topodata apresenta acurácia na obtenção desses dados pela resolução de $30 \mathrm{~m}$, similar à parcela empírica padrão da USLE de 22,13 m (Bhattarai \& Dutta 2007). Assim, a equação para estimativa do fator LS foi: $\mathrm{LS}=(a * \text { resolution } / 22,13)^{0,4 *}$ ( $\operatorname{sen} \theta / 0,0896)$, em que LS é o fator topográfico da teoria da potência do escoamento; $a$ é a área de contribuição hidrológica derivada do algoritmo D $\infty$ e da extensão TauDEM 5.0; e $\theta$ é a declividade em graus.

Para os usos e manejos presentes na sub-bacia do Córrego Pedra Branca (Figura 2B), foram obtidos da literatura especializada os valores do fator " $\mathrm{C}$ " (Tabela 2).

Na sub-bacia, a cultura do milho (outubro/ abril) é plantada em sucessão com a do feijão (maio/ setembro), sendo que os meses de dezembro e janeiro apresentam maior erosividade (em torno de 1.200 MJ mm ha-1 $\mathrm{h}^{-1}$ mês $^{-1}$ ), e, em junho e julho, a erosividade é de cerca de $50 \mathrm{MJ} \mathrm{mm} \mathrm{ha}^{-1} \mathrm{~h}^{-1}$ mês $^{-1}$ (Aquino et al. 2012). Assim, foi calculada a média ponderada pela erosividade, para o fator de cobertura

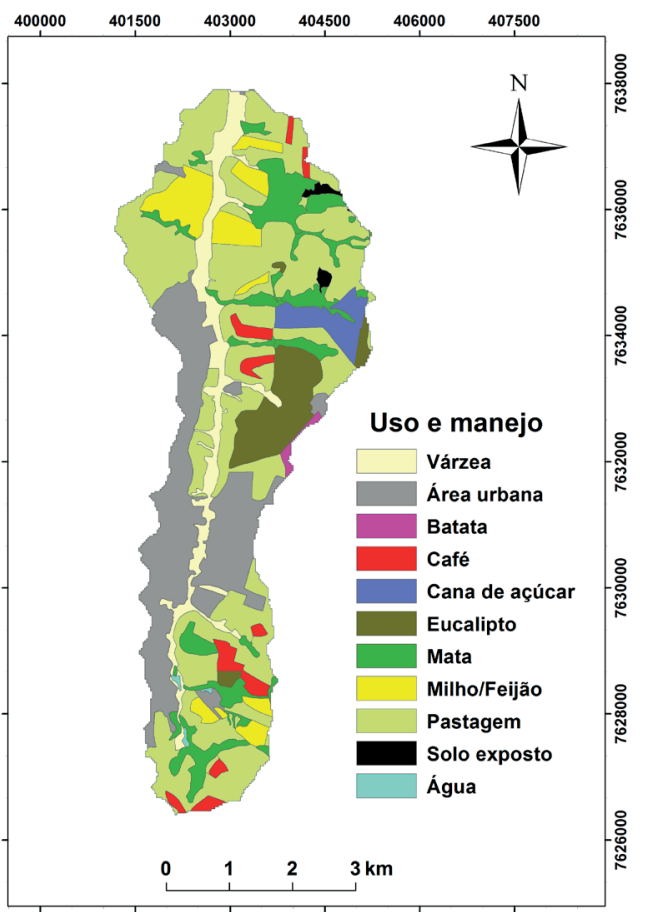

Figura 2. Declividade (A) e uso e manejo dos solos (B) da sub-bacia hidrográfica do Córrego Pedra Branca (Alfenas, MG, 2014). 
Tabela 2. Fatores C e P, para os usos e manejos presentes na sub-bacia hidrográfica do Córrego Pedra Branca (Alfenas, MG, 2014).

\begin{tabular}{llll}
\hline \multicolumn{1}{c}{ Uso e manejo } & Fator C & Fator P** & \multicolumn{1}{c}{ Autor } \\
\hline Café com arruamento de $3 \mathrm{~m}$ x $0,5 \mathrm{~m}$ & 0,1354 & 0,50 & Prochnow et al. (2005) \\
Café com arruamento de $3 \mathrm{~m}$ x 1 m* & 0,0866 & 0,50 & Prochnow et al. (2005) \\
Batata em desnível & 0,5000 & 1,00 & Fiener \& Auerswald (2006) \\
Batata em nível* & 0,2000 & 1,00 & Fiener \& Auerswald (2006) \\
Eucalipto & 0,3000 & 1,00 & Martins et al. (2010) \\
Eucalipto em plantio direto* & 0,3000 & 0,01 & Martins et al. (2010) \\
Milho & 0,1220 & 1,00 & De Maria \& Lombardi Neto (1997) \\
Milho em plantio direto* & 0,0280 & 0,01 & De Maria \& Lombardi Neto (1997) \\
Soja & 0,1437 & 1,00 & Bertol et al. (2001) \\
Soja em plantio direto* & 0,0455 & 0,01 & Bertol et al. (2001) \\
Milho + feijão & 0,1242 & 1,00 & Média ponderada soja + milho \\
Milho + feijão plantio direto* & 0,0271 & 0,01 & Média ponderada soja + milho \\
Cana-de-açúcar com queimada na colheita & 0,1420 & 0,50 & Andrade et al. (2011) \\
Cana-de-açúcar sem queimada na colheita* & 0,0960 & 0,50 & Andrade et al. (2011) \\
Pastagem degradada & 0,1000 & 1,00 & Roose (1977) \\
Pastagem conservada* & 0,0100 & 1,00 & Roose (1977) \\
Mata nativa & 0,0200 & 1,00 & Martins et al. (2010) \\
Área urbana & 0,0100 & 1,00 & Lim et al. (2011) \\
Várzea & 0,0004 & 1,00 & Oliveira et al. (2007) \\
Solo exposto & 1,0000 & 1,00 & \\
Corpos hídricos & 0,0000 & 0,00 & \\
\hline
\end{tabular}

* Valores utilizados na simulação da erosão; ** Valores de P obtidos de Bertoni \& Lombardi Neto (2008) e Roose (1977).

milho-feijão. Porém, como o fator de cobertura para feijão não foi encontrado na literatura, adotou-se o valor do fator da soja de Bertol et al. (2001), de características naturais similares às do feijão (Roloff \& Bertol 1998).

Para comparação com a erosão atual sob manejos convencionais, foi simulado um cenário com sistemas de manejo conservacionistas (Tabela 2).

As práticas conservacionistas "P" (Tabela 2) identificadas foram de plantio em nível no café e de terraceamento na cana-de-açúcar. Para todos os outros usos e manejos, foi usado o valor de $\mathrm{P}=1,00$. A prática de plantio direto com $\mathrm{P}=0,01$ (Roose 1977) foi adotada na simulação da erosão sob manejo conservacionista.

No ArcGIS 10.0, foi obtida a suscetibilidade à erosão hídrica da sub-bacia sob manejo convencional, pelo produto dos fatores naturais $\mathrm{R}, \mathrm{K}$ e LS e antrópicos $\mathrm{C}$ e P. Foi, ainda, simulada erosão sob manejos conservacionistas com $\mathrm{C}$ e $\mathrm{P}$ alternativos aos vigentes.

O limite de TPS foi calculado a partir de dados da Tabela 1 e de Brasil (1962), para as três unidades de Latossolos (Figura 1), e apurado pelos métodos de Lombardi Neto \& Bertoni (1975), Galindo \& Margolis (1989) e Bertol \& Almeida (2000). Para cada unidade de Latossolo, foi adotada a média dos três métodos, pois não há um método específico para a região estudada. Porém, os três métodos utilizados foram desenvolvidos em locais com abundância de Latossolos. O mapa de TPS foi gerado relacionando-se o mapa de unidades de solos (Figura 1) com o de erosão atual (Figura 3A), em que a TPS foi discriminada para cada unidade de Latossolo.

As taxas médias anuais de perda de solo sob os manejos convencional e conservacionista foram comparadas pelo teste t, a $5 \%$, com o auxílio do programa estatístico Sisvar (Ferreira 2014).

\section{RESULTADOS E DISCUSSÃO}

A área estudada apresenta erosão média de $8,40 \mathrm{Mg} \mathrm{ha}^{-1} \mathrm{ano}^{-1}$, com 34,80\% da área com valores acima do limite de TPS. A TPS calculada foi de 9,52 Mg ha ${ }^{-1}$ ano $^{-1}$, 9,99 Mg ha-1 ano ${ }^{-1}$ e $8,94 \mathrm{Mg} \mathrm{ha}^{-1}$ ano $^{-1}$, respectivamente para as unidades LVd1, LVd2 e LVd3 (Figura 3B). Tais valores de perda de solo são similares aos obtidos para Latossolos em uma área próxima e com características semelhantes às da sub-bacia estudada.

Neste estudo, também observou-se mais de 30 \% de área com perda de solo acima da TPS, 
como em Beskow et al. (2009). As perdas de solo na sub-bacia do Córrego Pedra Branca refletem a quantidade, frequência e intensidade das chuvas, com precipitação média de $1.500 \mathrm{~mm}^{2} \mathrm{ano}^{-1}$ e erosividade de $6.500 \mathrm{MJ} \mathrm{mm} \mathrm{ha}^{-1} \mathrm{~h}^{-1}$ ano $^{-1}$. Além disso, os manejos utilizados também podem elevar a degradação e a erosão dos solos.

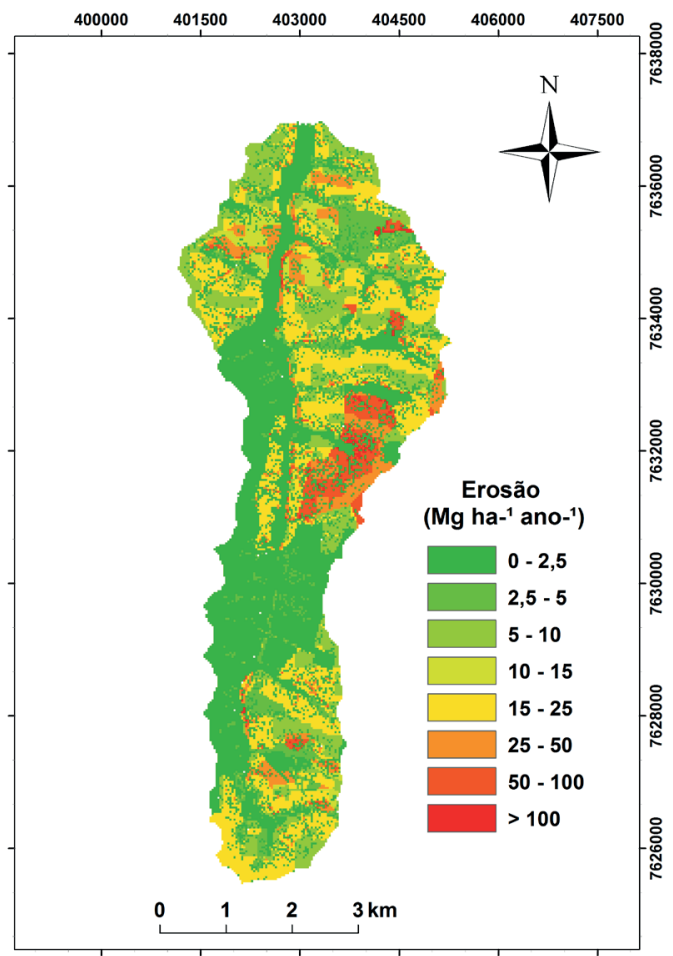

A Tabela 3 demonstra que a sub-bacia apresenta suscetibilidade de perda de solo de $23.688,00 \mathrm{Mg}$ ano $^{-1}$, com média de $8,40 \mathrm{Mg} \mathrm{ha}^{-1} \mathrm{ano}^{-1}$. As maiores perdas anuais ocorreram nas áreas de pastagem e de eucalipto (respectivamente $12.146 \mathrm{Mg} a n o^{-1} \mathrm{e}$ $5.167 \mathrm{Mg}$ ano $\left.^{-1}\right)$, com taxas médias de perdas anuais de $11,10 \mathrm{Mg} \mathrm{ha}^{-1} \mathrm{ano}^{-1}$ e $30,67 \mathrm{Mg} \mathrm{ha}^{-1}$ ano $^{-1}$, res-

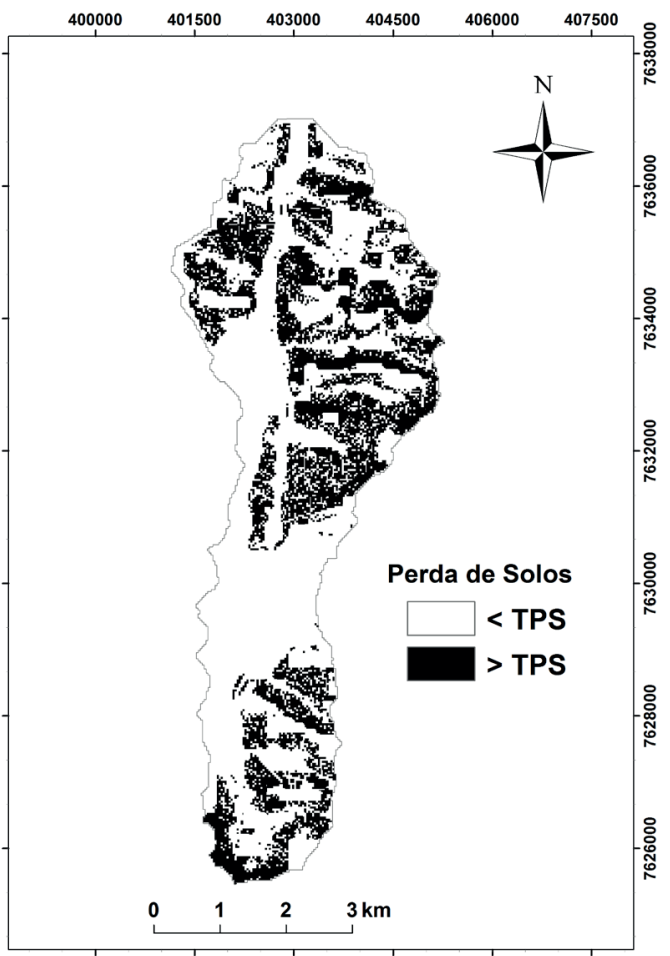

Figura 3. Mapas de erosão sob manejo convencional (A) e perda de solos (B) menor e maior do que o limite de TPS, na sub-bacia hidrográfica do Córrego Pedra Branca (Alfenas, MG, 2014).

Tabela 3. Suscetibilidade à perda de solo, para diferentes usos e manejos, na sub-bacia hidrográfica do Córrego Pedra Branca (Alfenas, MG, 2014).

\begin{tabular}{|c|c|c|c|c|c|c|c|c|}
\hline \multirow{3}{*}{ Uso } & \multirow[b]{2}{*}{ Área } & \multirow[b]{2}{*}{ Área } & \multicolumn{3}{|c|}{ Manejo convencional } & \multicolumn{3}{|c|}{ Manejo conservacionista } \\
\hline & & & $\begin{array}{l}\text { Taxa média de } \\
\text { perda de solo }\end{array}$ & $\begin{array}{l}\text { Perda total } \\
\text { de solos }\end{array}$ & $\begin{array}{l}\text { Contribuição no } \\
\text { total da erosão }\end{array}$ & $\begin{array}{l}\text { Taxa média de } \\
\text { perda de solo }\end{array}$ & $\begin{array}{l}\text { Perda total } \\
\text { de solos }\end{array}$ & $\begin{array}{l}\text { Contribuição no } \\
\text { total da erosão }\end{array}$ \\
\hline & ha & $\%$ & $\mathrm{Mg} \mathrm{ha}^{-1} \mathrm{ano}^{-1}$ & $\mathrm{Mg}_{\mathrm{ano}}{ }^{-1}$ & $\%$ & $\mathrm{Mg} \mathrm{ha}^{-1} \mathrm{ano}^{-1}$ & $\mathrm{Mg}$ ano $^{-1}$ & $\%$ \\
\hline Água & 4,25 & 0,16 & 0,00 & 0,00 & 0,00 & 0,00 & 0,00 & 0,00 \\
\hline Área urbana & 544,55 & 20,61 & 1,17 & 637,00 & 2,70 & 1,17 & 637,00 & 17,90 \\
\hline Batata & 8,81 & 0,33 & 56,17 & 495,00 & 2,10 & 21,29 & 188,00 & 5,30 \\
\hline Café & 79,34 & 3,00 & 9,31 & 739,00 & 3,10 & 5,59 & 444,00 & 12,40 \\
\hline Cana-de-açúcar & 71,00 & 2,68 & 9,37 & 665,00 & 2,80 & 6,10 & 433,00 & 12,20 \\
\hline Eucalipto & 168,42 & 6,37 & 30,68 & $5.167,00$ & 21,80 & 0,05 & 8,40 & 0,20 \\
\hline Mata & 219,82 & 8,32 & 2,47 & 543,00 & 2,30 & 2,47 & 543,00 & 15,20 \\
\hline Milho + feijão & 174,64 & 6,61 & 13,11 & $2.290,00$ & 9,80 & 0,01 & 1,70 & 0,10 \\
\hline Pastagem & $1.087,80$ & 41,16 & 11,17 & $12.146,00$ & 51,30 & 0,28 & 304,00 & 8,50 \\
\hline Solo exposto & 13,01 & 0,49 & 77,36 & $1.007,00$ & 4,30 & 77,36 & 1006,00 & 28,20 \\
\hline Várzea & 270,32 & 10,23 & 0,00 & 0,00 & 0,00 & 0,00 & 0,00 & 0,00 \\
\hline Total & $2.642,00$ & 100,00 & - & $23.688,00$ & 100,00 & - & $3.565,00$ & 100,00 \\
\hline
\end{tabular}


pectivamente. Porém, quando considerada a perda média por tipo de uso, constatou-se que as áreas mais suscetíveis à erosão hídrica são aquelas ocupadas pelas culturas de batata e de eucalipto e as de solos expostos, enquanto as menos suscetíveis são as de matas, várzea e urbana, esta última com elevadas perdas de água, devido à impermeabilização dos solos.

As perdas acima do limite de TPS (Figura 3B), considerando-se as classes adaptadas de Beskow et al. (2009) (Figura 3A), situam-se, principalmente, entre $10 \mathrm{Mg} \mathrm{ha}^{-1}$ ano $^{-1}$ e $25 \mathrm{Mg} \mathrm{ha}^{-1}$ ano $^{-1}$ e ocorrem nas áreas com manejo convencional, principalmente de eucalipto, batata, milho, cana-de-açúcar e pastagens. Já as perdas entre $25 \mathrm{Mg} \mathrm{ha}^{-1} \mathrm{ano}^{-1} \mathrm{e} 100 \mathrm{Mg} \mathrm{ha}^{-1} \mathrm{ano}^{-1}$ estão, sobretudo, em áreas de manejo convencional de eucalipto, batata e em algumas áreas de pastagens, milho, café e cana-de-açúcar, resultado da conjugação entre os fatores declividade (Figura 2A), uso e manejo (Figura 2B) e erodibilidade dos solos (Figura 4B). Observaram-se perdas concentradas, principalmente, na unidade LVd3, que possui maior erodibilidade entre os Latossolos, possivelmente devido aos menores teores de $\mathrm{MO}$ e CTC e maiores teores de silte, além de menores valores de DMG e de DMP, que podem acentuar o carreamento de partículas dos solos. Essa situação é agravada pelas queimadas na colheita da cana-de-açúcar e na limpeza dos terrenos, no inverno.

As perdas de solos sob eucalipto estão relacionadas aos quatro primeiros anos de desenvolvimento da planta, quando a cobertura do solo pelo dossel é baixa (Martins et al. 2010). Além disso, as áreas usadas, em geral, são íngremes, exigindo manejos e práticas conservacionistas eficazes, como, por exemplo, o terraceamento.

Nas áreas de culturas temporárias, a adoção de técnicas de cultivo em nível e plantio direto, dentre outras, pode ajudar na prevenção à erosão. As elevadas perdas de solos, nas áreas de pastagens, resultam das queimadas e do pastejo sob lotação contínua, que podem ser mitigados com a adoção do pastejo rotacionado, diminuição do número de cabeças de gado por hectare e adubação dos solos, para elevar a produtividade do pasto, aumentando a cobertura do solo.

O uso da equação USPED, combinada ao programa de Tarboton \& Mohammed (2010), para identificação da direção e concentração do fluxo e escoamento superficial, identifica, com acurácia, as áreas de escoamento e de acúmulo de fluxo, bem como as áreas potenciais de acúmulo de sedimentos,
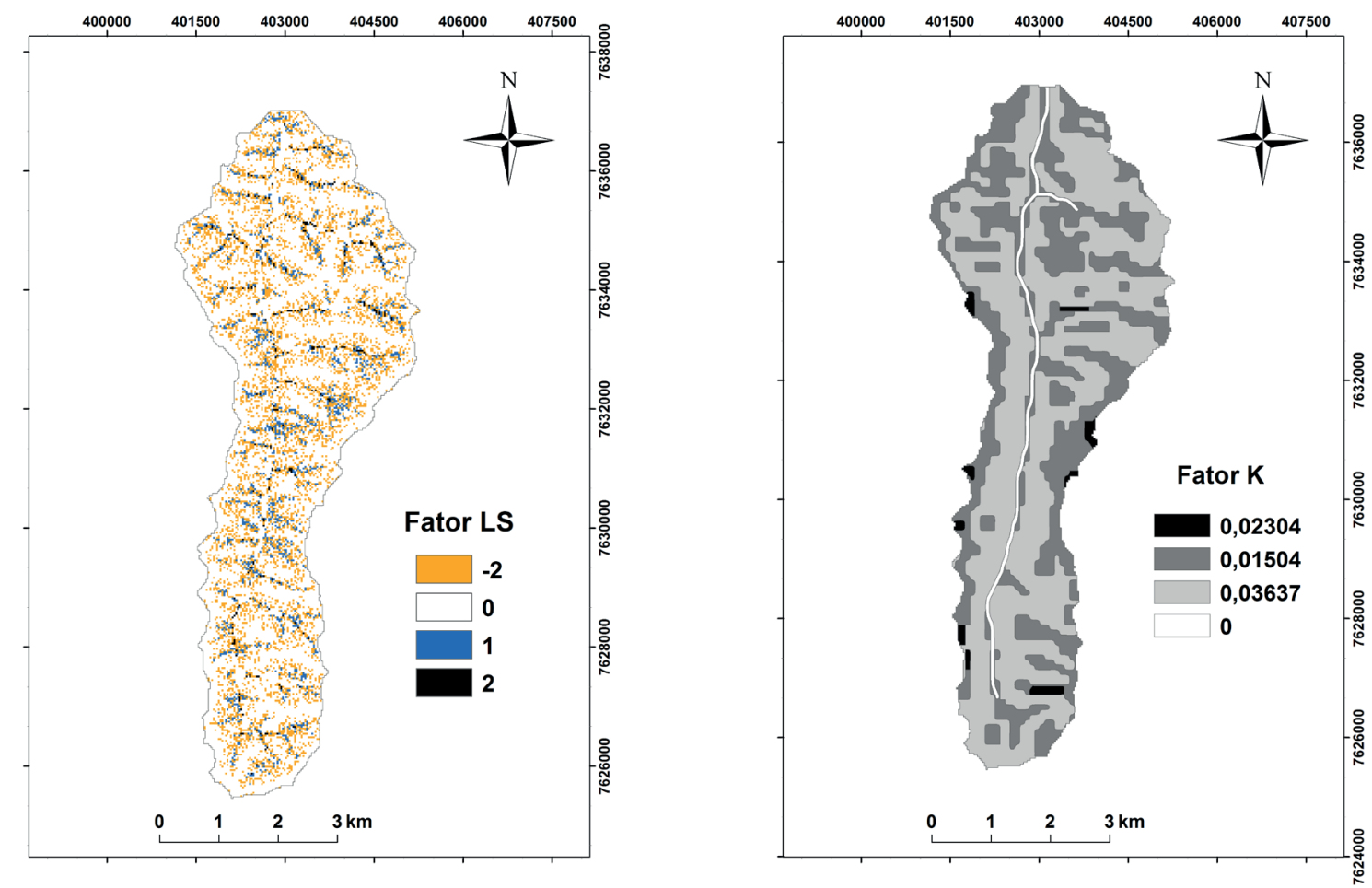

Figura 4. Mapas do fator topográfico - LS (A) e da erodibilidade do solo - K (B) da sub-bacia hidrográfica do Córrego Pedra Branca (Alfenas, MG, 2014). 
que recebem valores negativos para o fator LS (Oliveira et al. 2013) (Figura 4A). Porém, como não há erosão negativa, foi atribuído valor de erosão zero para as áreas de acúmulo de fluxo e sedimentos.

Os solos são ácidos (pH entre 4,700 e 5,080) e apresentam textura de média a argilosa e, em média, baixa CTC-T $\left(7,690-9,840 \mathrm{cmol}_{\mathrm{c}} \mathrm{dm}^{-3}\right)$, CTC-t de 1,630-2,270 $\mathrm{cmol}_{\mathrm{c}} \mathrm{dm}^{-3} \mathrm{eV}$ média de 17,90\%(Tabela 1). Possuem, ainda, baixa disponibilidade de $\mathrm{P}$ (média de 2,058 $\left.\mathrm{mg} \mathrm{dm}^{-3}\right), \mathrm{Mg}$ de $0,230-0,580 \mathrm{cmol}_{\mathrm{c}} \mathrm{dm}^{-3} \mathrm{e}$ teores baixos de $\mathrm{Ke} \mathrm{N}$. Essas características resultam do intemperismo sob regime hídrico údico, com menos de três meses secos e precipitação média de $1.500 \mathrm{~mm} \mathrm{ano}^{-1}$, que, ao longo do tempo, promoveu a lixiviação das bases e do silício do solo, causando o enriquecimento relativo do solo em alumínio das rochas parentais, além de teores elevados de $\mathrm{H}+\mathrm{Al}$ (média de $8 \mathrm{cmol}_{\mathrm{c}} \mathrm{dm}^{-3}$ ) e de saturação de $\mathrm{Al}(\mathrm{m})$ (média de $40 \%$ ). Adicionalmente, a redução do teor de $\mathrm{MO}$, em função do desmatamento e das queimadas, diminui a deposição de detritos vegetais e contribui para a redução da capacidade de troca de bases desses solos (Brasil 1962).

Essas características e a limitada capacidade adsortiva de cátions da caulinita e gibbsita, devido às baixas superfícies específicas, resultam em baixos teores de K, P, Ca, Mg, CTC-T, CTC-t, SB e $\mathrm{V}$ (Tabela 1) e explicam o comportamento distinto das argilas tropicais. A alta floculação dessas argilas sobrepuja o efeito da textura, aumentando a infiltração, em detrimento do escoamento superficial (Brasil 1962, Vitorino et al. 2003).

Entretanto, nos Latossolos estudados (Tabela 1), o índice de floculação ficou abaixo do padrão dos Latossolos tropicais, o que pode ter resultado do manejo inadequado e da ausência de práticas de conservação, que favorecem a desagregação da estrutura do solo e induzem a uma baixa permeabilidade na área, com valores de 17,060-59,980 $\mathrm{mm} \mathrm{h}^{-1}$. Assim, os baixos teores de MO (média de 27,35 $\mathrm{g} \mathrm{kg}^{-1}$ ) coincidem com os valores médios a baixos de DMP $(3,000 \mathrm{~mm})$ e DMG $(4,900 \mathrm{~mm})$ e o baixo grau de floculação (30 \%) (Tabela 1), quando comparados à literatura especializada. Disso resulta uma estrutura com menor aeração, infiltração e movimento de água no perfil do solo, favorecendo a erosão e prejudicando o crescimento de raízes e plantas (FAO 2005).

Diante disso, a simulação da erosão sob sistemas de manejo conservacionistas (Figura 5) avaliou a eficiência de técnicas que poderiam combater a erosão acelerada e melhorar os atributos físicos dos solos. Por conseguinte, as práticas conservacionistas simuladas poderiam reduzir a taxa média de erosão de $8,40 \mathrm{Mg} \mathrm{ha}^{-1}$ ano $^{-1}$ para 2,84 $\mathrm{Mg} \mathrm{ha}^{-1}$ ano $^{-1}$ e diminuir a área acima do limite da TPS de 34,80\% para 4,00\%, ou seja, de 914 ha para 106 ha. Assim, a diferença anual nas taxas médias de perda de solo, entre os manejos convencional e conservacionista, foi significativa, de acordo com o teste $\mathrm{t}$ $(\mathrm{p}<0,0001)$.

A comparação entre a Tabela 4 e as Figuras 5 e 3A ilustra que o manejo sob plantio direto é o mais eficiente na redução da erosão. Entretanto, outros sistemas de manejo conservacionistas, como a colheita da cana-de-açúcar sem queimadas e o arruamento de $3 \mathrm{~m} \times 1 \mathrm{~m}$ dos cafezais, também reduziriam a erosão, demonstrando ser viável conciliar produção e preservação. As áreas que seguiram acima do limite da TPS (Figura 5), ou seja, acima de $10 \mathrm{Mg} \mathrm{ha}^{-1}$ ano $^{-1}$, foram as de solos expostos e com cultivos de café, cana-de-açúcar e batata, na unidade de solo LVd3.

A estimativa da suscetibilidade à erosão de 23.6881,00 Mg ano-1, na sub-bacia do Córrego Pedra Branca, pode contribuir para elevar as taxas de

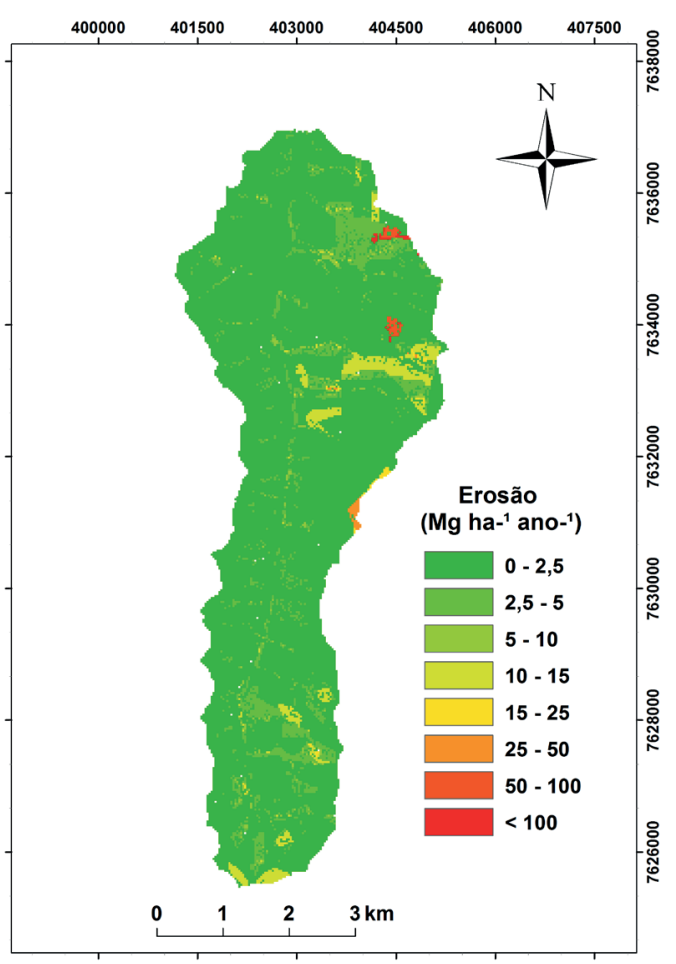

Figura 5. Erosão simulada com a adoção de manejo conservacionista, na sub-bacia hidrográfica do Córrego Pedra Branca (Alfenas, MG, 2014). 
Tabela 4. Taxas de erosão sob manejos convencionais e conservacionistas, na sub-bacia hidrográfica do Córrego Pedra Branca (Alfenas, MG, 2014).

\begin{tabular}{cccccl}
\hline \multirow{2}{*}{$\begin{array}{c}\text { Taxa de perda } \\
\text { de solos }\end{array}$} & \multicolumn{2}{c}{ Manejo convencional } & \multicolumn{2}{c}{ Manejo conservacionista } & \multirow{2}{*}{ Classes de erosão dos solos* } \\
\cline { 2 - 4 } Mg ha $^{-1}$ ano $^{-1}$ & \multicolumn{1}{c}{ Área } & Área & Área & Área & \\
\hline $0,0-2,5$ & $1.198,81$ & 45,37 & $2.305,18$ & 86,23 & Suave \\
$2,5-5,0$ & 145,10 & 5,49 & 229,11 & 8,67 & Suave/moderada \\
$5,0-10,0$ & 378,50 & 14,31 & 27,84 & 1,05 & Moderada \\
$10,0-15,0$ & 73,01 & 2,76 & 83,88 & 3,16 & Moderada alta \\
$15,0-25,0$ & 564,90 & 21,38 & 6,98 & 0,26 & Alta \\
$25,0-50,0$ & 165,71 & 6,27 & 5,53 & 0,20 & Muito alta \\
$50,0-100,0$ & 96,50 & 3,65 & 6,62 & 0,25 & Altamente severa \\
$>100,0$ & 13,96 & 0,52 & 3,71 & 0,14 & Extremamente severa \\
\hline Total & $2.642,00$ & 100,00 & $2.642,00$ & 100,00 & \\
\hline
\end{tabular}

* Adaptadas de Beskow et al. (2009).

assoreamento do reservatório da Usina Hidrelétrica de Furnas, diminuindo a capacidade de geração de energia elétrica. Atualmente, os usos e os manejos inadequados dos solos têm impactos diretos na perda de solo (Figura 3A, Tabelas 2 e 4) e no aumento dos custos da produção agropecuária. No entanto, os impactos deletérios indiretos também devem ser considerados, com destaque para o assoreamento e a diminuição da capacidade útil dos reservatórios, eutrofização dos corpos d'água, contaminação da cadeia trófica com agrotóxicos e, conforme Carvalho et al. (2010), aumento das emissões de gases de efeito estufa.

A degradação dos recursos ambientais desencadeia efeitos negativos sobre todos os recursos físicos e biológicos da ecosfera terrestre (Morgan \& Nearing 2011). Assim, essa degradação de tais recursos deve ser minimizada, em áreas com ação antrópica, pelo uso de práticas de manejo conservacionistas simples, como o plantio direto e o plantio em nível.

\section{CONCLUSÕES}

1. O manejo convencional e a fragmentação florestal são as principais causas de degradação do solo e aumento das taxas de erosão dos Latossolos Vermelhos distróficos, atingindo valores acima do limite de tolerância de perda de solo.

2. Na sub-bacia hidrográfica do Córrego Pedra Branca, devido à ausência de manejos conservacionistas, as áreas que possuem maior perda média por hectare são as de cultivos convencionais de batata e eucalipto, com cultivo morro abaixo, e as de solos expostos. As pastagens também apresentam elevadas perdas médias, devido ao manejo em lotação contínua.

3. No cenário conservacionista simulado, o plantio direto seria o mais eficiente no combate à erosão hídrica, em comparação a todos os outros manejos da sub-bacia. Outras práticas associadas também contribuiriam para a redução das taxas de erosão, tais como a colheita da cana-de-açúcar sem queimadas, arruamento dos cafezais plantados em espaçamento de $3 \mathrm{~m}$ x $1 \mathrm{~m}$ e adoção do plantio em nível, no cultivo de batata.

\section{AGRADECIMENTOS}

À Coordenação de Aperfeiçoamento de Pessoal de Nível Superior (Capes), pelas bolsas de mestrado, e à Consultoria Santiago e Cintra, pelo fornecimento das imagens de satélite.

\section{REFERÊNCIAS}

ANDRADE, N. S. F.; MARCÍLIO, V. M. F.; JOSÉ, L. R. T. Impacto técnico e econômico das perdas de solo e nutrientes por erosão no cultivo da cana-de-açúcar. Engenharia Agrícola, Jaboticabal, v. 31, n. 3, p. 539-550, 2011.

AQUINO, R. et al. Spatial variability of the rainfall erosivity in southern region of Minas Gerais State, Brazil. Ciência e Agrotecnologia, Lavras, v. 36, n. 5, p. 533-542, 2012.

AVANZI, J. C. et al. Spatial distribution of water erosion risk in a watershed with eucalyptus and Atlantic Forest. 
Ciência e Agrotecnologia, Lavras, v. 37, n. 5, p. 427-434, 2013.

BARRETTO,A. G. O.P.; BARROS, M. G. E.; SPAROVEK, G. Bibliometria, história e geografia da pesquisa brasileira em erosão acelerada do solo. Revista Brasileira de Ciência do Solo, Viçosa, v. 32, n. 6, p. 2443-2460, 2008.

BERTOL, I.; ALMEIDA, J. A. Tolerância de perda de solo por erosão para os principais solos do Estado de Santa Catarina. Revista Brasileira de Ciência do Solo, Viçosa, v. 24, n. 3, p. 657-668, 2000.

BERTOL, I.; SCHICK, J.; BATISTELA, O. Razão de perdas de solo e fator $\mathrm{C}$ para as culturas de soja e trigo em três sistemas de preparo em um Cambissolo Húmico alumínico. Revista Brasileira de Ciência do Solo, Viçosa, v. 26, n. 2, p. 545-552, 2001.

BERTONI, J.; LOMBARDI NETO, F. Conservação do solo. 6. ed. São Paulo: Ícone, 2008.

BESKOW, S. et al. Soil erosion prediction in the Grande River Basin, Brazil, using distributed modeling. Catena, Amsterdam, v. 79, n. 1, p. 49-59, 2009.

BHATTARAI, R.; DUTTA, D. Estimation of soil erosion and sediment yield using GIS at catchment scale. Water Resources Management, Amsterdam, v. 21, n. 10, p. 16351647, 2007.

BLACK, C. A. (Ed.). Methods of soil analysis. Part I: physical and mineralogical methods. 2. ed. Madison: Soil Science Society of America, 1986.

BRADY, N. C.; WEIL, R. R. Elementos da natureza e propriedades dos solos. Porto Alegre: Bookman, 2013.

BRASIL. Empresa de Pesquisa Energética. Balanço energético 2013: ano base 2012. Brasília, DF: Ministério de Minas e Energia, 2013.

BRASIL. Ministério da Agricultura. Levantamento de reconhecimento dos solos da região sob influência do reservatório de Furnas. Rio de Janeiro: Ministério da Agricultura, 1962.

CARVAlHO, J. L. N. et al. Potencial de sequestro de carbono em diferentes biomas brasileiros. Revista Brasileira de Ciência do Solo, Viçosa, v. 34, n. 2, p. 277 289, 2010.

CARVALHO, N. O. Hidrossedimentologia prática. 2. ed. Rio de Janeiro: Interciência, 2008.

DANE, J. H.; TOPP, G. C. Methods of soil analysis: part 4 - physical methods. Madison: Soil Science Society of America, 2002.

DE MARIA, I. C.; LOMBARDI NETO, F. Razão de perdas de terra e fator $\mathrm{C}$ para sistemas de manejo da cultura do milho. Revista Brasileira de Ciência do Solo, Campinas, v. 21, n. 1, p. 263-270, 1997.
EMPRESA BRASILEIRA DE PESQUISA AGROPECUÁRIA (Embrapa). Análises químicas para avaliação da fertilidade do solo: métodos usados na Embrapa Solos. Rio de Janeiro: Embrapa Solos, 1998.

EMPRESA BRASILEIRA DE PESQUISA AGROPECUÁRIA (Embrapa). Sistema brasileiro de classificação de Solos. 2. ed. Rio de Janeiro: Embrapa Solos, 2006.

FERREIRA, D. F. Sisvar: a guide for its bootstrap procedures in multiple comparisons. Ciência e Agrotecnolgia, Lavras, v. 38 , n. 2, p. 109-112, 2014.

FIENER, P.; AUERSWALD, K. Rotation effects of potato, maize and winter wheat on water erosion from cultivated land. In: HORN, R. et al. (Eds.). Soil management for sustainability. Reiskirchen: Catena Verlag GMBH, 2006. p. 273-280.

FOOD AND AGRICULTURE ORGANIZATION OF THE UNITED NATIONS (FAO). The importance of soil organic matter: key to drought-resistant soil and sustained food and production. Roma: FAO, 2005.

FUNDAÇÃO JOÃO PINHEIRO (FJP). Produto interno bruto das regiões de planejamento de Minas Gerais. 2009. Disponível em: <http://www.fjp.mg.gov.br /índex.php/ analise-economica/pib-produto-interno-bruto-de-minasgerais $>$. Acesso em: 16 abr. 2013.

GALINDO, I. C. L.; MARGOLIS, E. Tolerância de perdas por erosão para solos do Estado de Pernambuco. Revista Brasileira de Ciência do Solo, Campinas, v. 13, n. 1, p. 95-100, 1989.

HASUI, Y. A grande colisão pré-cambriana do Sudeste brasileiro e a estruturação regional. Geociências, São Paulo, v. 29, n. 2, p. 141-169, 2010.

INSTITUTO NACIONAL DE PESQUISAS ESPACIAIS (INPE). Atlas dos municípios da Mata Atlântica: período 2011-2012. São Paulo: INPE, 2013.

KEMPER, W. D.; CHEPIL, W. S. Size distribution of aggregates. In: BLACK, C. A. (Ed.). Methods of soil analysis: part 1. 2. ed. Madison: Soil Science Society of America, 1965. p. 495-509.

KEMPER, W. D.; ROSENAU, R. C. Aggregate stability and size distribution. In: KLUTE, A. (Ed.). Methods of soil analysis. Madison: Soil Science Society of America, 1986. p. 425-442.

LIM, K. J. et al. SATEEC GIS: system for spatiotemporal analyses of soil erosion and sediment yield. In: GODONE, D.; STANCHI, S. (Eds.). Soil erosion studies. Rijeka: InTech, 2011. p. 111-119.

LOMBARDI NETO, F.; BERTONI, J. Tolerância de perdas de terra para solos do Estado de São Paulo. Campinas: Instituto Agronômico, 1975. (Boletim técnico, 28). 
LONDRES, F. Agrotóxicos no Brasil: um guia para ação em defesa da vida. Rio de Janeiro: Assessoria e Serviços a Projetos em Agricultura Alternativa, 2011.

MARTINS, S. G. et al. Fator cobertura e manejo do solo e perdas de solo e água em cultivo de eucalipto e em Mata Atlântica nos Tabuleiros Costeiros do Estado do Espírito Santo. Scientia Forestalis, Piracicaba, v. 38, n. 87, p. $517-$ 526, 2010.

MINAS GERAIS. Fundação Estadual do Meio Ambiente. Mapa de solos do Estado de Minas Gerais. 2010. Disponível em: <http:// www.feam.br/noticias/1/949mapas-de-solo-do-estado-deminas-gerais $>$. Acesso em: 03 out. 2012.

MOORE, I. D.; BURCH, F. J. Physical basis of the lengthslope factor in the Universal Soil Loss Equation. Soil Science Society of America Journal, Madison, v. 50, n. 5, p. 1294-1298, 1986.

MORGAN, R. P. C.; NEARING, M. A. (Eds.). Handbook of erosion modeling. West Sussex: Wiley-Blackwell, 2011.

OLIVEIRA, A. H. et al. Development of topographic factor modeling for application in soil erosion models. In: SORIANO, M. C. H. (Ed.). Soil processes and current trends in quality assessment. Rijeka: In Tech, 2013.

OLIVEIRA, A. M. M.; PINTO, S. A. F.; LOMBARDI NETO, F. Caracterização de indicadores da erosão do solo em bacias hidrográficas com o suporte de geotecnologias e modelo preditivo. Estudos Geográficos, Rio Claro, v. 5, n. 1, p. 63-86, 2007.

PROCHNOW, D. et al. Razão de perdas de terra e fator $\mathrm{C}$ da cultura do cafeeiro em cinco espaçamentos, em Pindorama (SP). Revista Brasileira de Ciência do Solo, Viçosa, v. 29, n. 1, p. 91-98, 2005.

RENARD, K. G. et al. Predicting soil erosion by water: a guide to conservation planning with the Revised Universal Soil Loss Equation (RUSLE). Washington, DC: U. S. Department of Agriculture, 1997.

ROLOFF, G.; BERTOL, O. J. Método para a estimativa da cobertura do solo e da altura do dossel de algumas culturas de verão. Revista Brasileira de Ciência do Solo, Viçosa, v. 22, n. 2, p. 319-327, 1998.
ROOSE, E. J. Application of the Universal Soil Loss Equation of Wischmeier and Smith in West Africa. In: GREENLAND, D. J.; LAL, R. (Eds.). Soil conservation and management in the humid tropics. Chichester: John Wiley \& Sons, 1977. p. 177-187.

SILVA, M. L. N. et al. Proposição de modelos para estimativa da erodibilidade de Latossolos brasileiros. Pesquisa Agropecuária Brasileira, Brasília, DF, v. 34, n. 12, p. 2287-2298, 1999.

SPAROVEK, G.; VAN LIER, Q. J.; DOURADO NETO, D. Computer assisted Köppen climate classification: a case study for Brazil. International Journal of Climatology, Chichester, v. 27, n. 2, p. 257-266, 2007.

TARBOTON, D. A new method for the determination of flow directions and contributing areas in grid digital elevation models. Water Resources Research, Washington, DC, v. 33, n. 2, p. 309-319, 1997.

TARBOtOn, D. G.; MOHAMMED, I. N. Software TauDem 5.0: terrain analysis using digital elevation models. 2010. Disponível em: $<$ http://hydrology.usu. edu/taudem/taudem5/ downloads.html $>$. Acesso em: 23 ago. 2013.

UNITED NATIONS POPULATION FUND (UNFPA). Relatório sobre a situação da população mundial 2012. Nova York: ONU, 2012.

VITORINO, A. C. T. et al. Mineralogia, química e estabilidade de agregados do tamanho de silte de solos da Região Sudeste do Brasil. Pesquisa Agropecuária Brasileira, Brasília, DF, v. 38, n. 1, p. 133-141, 2003.

WISCHMEIER, W. H.; SMITH, D. D. Predicting rainfall erosion losses: a guide to conservation planning. Washington, DC: United States Department of Agriculture, 1978.

ZHANG, R. Determination of soil sorptivity and hydraulic conductivity from the disk infiltrometer. Soil Science Society of America Journal, Madison, v. 61, n. 4, p. 10241030, 1997.

ZOLIN, C. A. et al. Minimização da erosão em função do tamanho e localização das áreas de floresta no contexto do programa "conservador das águas". Revista Brasileira de Ciência do Solo, Viçosa, v. 35, n. 6, p. 2157-2166, 2011. 